\title{
Structural Typing of Systemic Amyloidoses by Luminescent-Conjugated Polymer Spectroscopy
}

\author{
K. Peter R. Nilsson, ${ }^{\star \dagger}$ Kristian Ikenberg, ${ }^{\ddagger}$ \\ Andreas Åslund, ${ }^{\dagger}$ Sophia Fransson, ${ }^{*}$ \\ Peter Konradsson, ${ }^{\dagger}$ Christoph Röcken, ${ }^{\S}$ \\ Holger Moch, ${ }^{\ddagger}$ and Adriano Aguzzi* \\ From the Institutes of Neuropathology, " and Surgical Pathology, \\ Department of Pathology, University Hospital of Zurich, Zurich, \\ Switzerland; the Department of Chemistry, ${ }^{\dagger}$ Linköping University, \\ Sweden; and the Institute of Pathology, ${ }^{\S}$ Christian-Albrechts- \\ University, Kiel, Germany
}

Most systemic amyloidoses are progressive and lethal, and their therapy depends on the identification of the offending proteins. Here we report that luminescent-conjugated thiophene polymers (LCP) sensitively detect amyloid deposits. The heterodisperse polythiophene acetic acid derivatives, polythiophene acetic acid (PTAA) and trimeric PTAA, emitted yellowred fluorescence on binding to amyloid deposits, whereas chemically homogeneous pentameric formic thiophene acetic acid emitted green-yellow fluorescence. The geometry of LCPs modulates the spectral composition of the emitted light, thereby reporting ligand-induced steric changes. Accordingly, a screen of PTAA-stained amyloid deposits in histological tissue arrays revealed striking spectral differences between specimens. Blinded cluster assignments of spectral profiles of tissue samples from 108 tissue samples derived from 96 patients identified three nonoverlapping classes, which were found to match AA, AL, and ATTR immunotyping. We conclude that LCP spectroscopy is a sensitive and powerful tool for identifying and characterizing amyloid deposits. (Am J Pathol 2010, 176:563-574; DOI: 10.2353/ajpath.2010.080797)

Amyloidoses are diseases of disparate etiologies characterized by extracellular proteinaceous deposits in tissues and organs. These deposits, termed "amyloids," result from misfolding and/or partial unfolding of proteins followed by their ordered aggregation. At least 27 different proteins have been reported to form disease-associated amyloids in vivo ${ }^{1}$, and there is evidence that any given polypeptide can be induced to form amyloid in vitro under appropriate conditions. ${ }^{2}$ It has been suggested that amyloid may represent a primordial state for all proteins, which would be always attained unless specific antiamyloidogenic factors (including chaperones and disaggregases) prevent or revert its formation. Accordingly, formation of amyloids may be much more prevalent than currently appreciated ${ }^{3}$ and may contribute to several diseases whose etiology is hitherto unclear. ${ }^{4}$

Some amyloids are highly selective in their organ tropism and lead to localized amyloidosis. Two highly prevalent organ-specific amyloidoses are caused by the $A \beta$ peptide ${ }^{5}$ and islet amyloid polypeptide, which are associated with Alzheimer's disease and type 2 diabetes, respectively. Prion diseases, which go along with aggregation of PrPSc, can be regarded as transmissible amyloidoses of the nervous and lymphoreticular system. ${ }^{6}$ Other amyloidogenic proteins deposit in many organs. Such "systemic" amyloidoses can be neoplastic, inflammatory, or genetic in origin and present as chronic progressive diseases leading to lethal heart and renal failure if untreated. Depending on the biochemical nature of the amyloid in question, the average survival can be as short as 12 months, or can span $7-15$ years.

Therapeutic options for amyloidoses include aggressive treatments directed at reducing precursor protein production and/or at inhibiting the extracellular deposi-

Supported by grants of the European Union (TSEUR), the Stammbach Foundation (to A.Aguzzi), the Swiss National Science Foundation (to A.Aguzzi), the National Competence Center for Research on Neural Plasticity and Repair (to A.Aguzzi), Novartis Foundation (to A.Aguzzi), the Foundation for Research at the University of Zürich (to K.P.R.N.), the Knut and Alice Wallenberg Foundation (to K.P.R.N.), and the Swedish Foundation for Strategic Research (to K.P.R.N.).

K.P.R.N. and K.I. contributed equally to this work.

K.P.R.N. has ownership in a company, BioChromix (Stockholm, Sweden), which is commercializing the technique describe in the paper

Accepted for publication October 20, 2009.

Supplemental material for this article can be found on http://ajp. amjpathol.org.

Address reprint requests to Prof., Dr. Adriano Aguzzi, M.D., or Prof., Dr. Holger Moch, M.D., Department of Pathology, University of Zurich, Schmelzbergstrasse 12, CH-8091 Zurich, Switzerland. E-mail: adriano.aguzzi@ usz.ch or holger.moch@usz.ch. 
tion of amyloid fibrils, eg, by pharmacological immunosuppression or even by surgical replacement of the organ synthesizing the precursor protein. The indication for each of these therapies, and their prognostic prospect, depend on the specific type of amyloid. ${ }^{7,8}$ As optimal outcomes rely on early therapy, sensitive methods for diagnosis and selective technologies for identification of amyloid subtypes are of greatest importance.

Systemic amyloidoses are classified according to the chemical nature of the predominant amyloid constituent, with the most common amyloids being $\mathrm{AL}, \mathrm{AA}$, and ATTR. ${ }^{9,10} \mathrm{AL}$ amyloid consists of Ig light chains, or fragments thereof, and is associated with various B cell lymphoproliferative disorders including multiple myeloma. ${ }^{10-13}$ AA amyloid is derived from serum amyloid $A$ (AA) protein and is associated with chronic immune activation, as in chronic infections, autoimmune or hereditary inflammatory diseases, or cancer. ${ }^{14,15}$ ATTR systemic amyloid consists of transthyretin deposits and occurs sporadically or in association with transthyretin mutations that enhance protein misfolding and fibril formation. ${ }^{16-19}$

Amyloid deposits consist of fibrils of 7-10 nm in diameter displaying a cross $\beta$-pleated sheet conformation. This common structural property has enabled the development of generic amyloid ligands, such as Congo Red and thioflavins. The gold-green birefringence of Congo Red-stained amyloid is commonly considered the diagnostic gold standard. However, small amyloid ligands do not differentiate between amyloid subtypes. Hence, the biochemical classification of amyloids must be pursued by other means.

In hereditary amyloidoses, certainty can be attained by identifying causative mutations in the genes encoding the respective precursor protein. Mass spectrometric identification of amyloid-derived peptides can be diagnostic, but it is far too cumbersome for routine clinical diagnostics. Therefore, immunohistochemical stains are typically used for differentiating amyloid subtypes. ${ }^{13}$ However, immunohistochemistry is fraught with specific problems. Most antibodies penetrate only poorly the compact amyloid structures. Also, many amyloids incorporate Igs and complement-derived opsonins, which can give rise to false-positive stains with diagnostic antibodies and-in worst-case scenarios-may lead to misdiagnoses. ${ }^{13,20-23}$

We have previously reported that luminescent-conjugated polymers (LCPS) interact with amyloid fibrils and amyloid deposits in tissue sections. ${ }^{24-26}$ Whereas conventional amyloid ligands, such as Congo Red and thioflavin derivatives, are sterically rigid and fluoresce with defined spectra, LCPs are composed of rotationally flexible polythiophene chains that fluoresce in different colors depending on their geometry. Therefore, the emission spectra recorded from LCPs reflect the conformation of their backbones. The interaction of LCPs with protein aggregates imposes rotational constraints leading to spectroscopic signatures indicative of specific supramolecular structures. This phenomenon allows for discriminating mouse-passaged prion strains that may solely differ in their structure. ${ }^{27}$ Analogously, we were able to differentiate multiple heterogeneous types of $A \beta$ deposits in the brain of transgenic mice. ${ }^{28}$

Here we tested the usefulness of three anionic LCPs, polythiophene acetic acid (PTAA), trimeric polythiophene acetic acid (tPTAA), and pentameric formic thiophene acetic acid (p-FTAA) for the typing of human systemic amyloidoses. We found that the analysis of spectral signatures of anionic LCPs provide complementary information to conventional techniques regarding the nature of the amyloid deposits and that LCP fluorescence provides a more precise readout than the polarized absorbance of Congo Red. Hence, LCPs represent a complementary tool for rapid and accurate diagnosis of systemic amyloidoses.

\section{Materials and Methods}

\section{Patients}

Patients diagnosed with amyloidosis during the period from 1996 to 2007 were identified in the archives of the Institute of Surgical Pathology (Zurich, Switzerland). We chose 54 paraffin-embedded tissue blocks with conspicuous amyloid deposits from 42 patients, including 10 women and 32 men. Clinical information was retrieved from hospital records. The mean age at diagnosis was 70.5 years (range, 17-96 years). The tissue samples of the 42 patients with systemic amyloidosis included heart $(n=27)$, kidney $(n=4)$, tongue $(n=1)$, esophagus $(n=$ $1)$, seminal vesicle $(n=1)$, stomach $(n=2)$, soft tissue $(n=2)$, lymph node $(n=1)$, lung $(n=2)$, sigma colon $(n=1)$, small intestine $(n=1)$, duodenum $(n=2)$, conjunctiva $(n=1)$, liver $(n=1)$, colon $(n=1)$, prostate $(n=1)$, thyroid $(n=1)$, adrenal gland $(n=1)$, parathyroid $(n=1)$, and joint capsule $(n=2)$. All tissue specimens were fixed in $4 \%$ formalin and embedded in paraffin. The present study was performed according to the ethical rules for establishments of novel diagnostic tests in the Kanton Zurich under strictly unlinked-anonymous conditions.

A "validation set" of amyloid specimens was retrieved from the Amyloid Registry of the Charité University Hospital (Berlin, Germany) and included 54 patients with histologically confirmed amyloid (37 males, 17 females; mean age, 66.4 years; range, $42-86$ years). The tissue samples were obtained from the heart (17 cases), colon and rectum (12), stomach (5), liver (4), kidney (3), iliac crest (3), lung (2), skin (2), lymph node (1), small intestine (1), tendons (1), thyroid gland (1) tongue (1), and ureter (1). All specimens had been fixed in formalin and embedded in paraffin.

\section{Histology and Immunohistochemistry}

In each sample selected for this study, the presence of amyloid was confirmed by histological examination of the birefringence of deparaffinized, Congo Red-stained sections. The quality of the tissue material and amount of amyloid deposits were documented for each sample. Amyloid subtypes were classified by immunohistochem- 
istry with a broad panel of reagents including commercially available primary monoclonal or polyclonal antibodies. Antibodies against AA (diluted 1/500; monoclonal), transthyretin (TTR) (1/800; polyclonal), human kappa light chains ( $\kappa$; polyclonal), and lambda light chains $(\lambda$; polyclonal) were purchased from Dako (Glostrup, Denmark). Primary monoclonal antibodies against human kappa $(\kappa)$ and lambda $(\lambda)$ light chains (1/50) were purchased from BMA Biomedicals (Augst, Switzerland). Staining of the tissue microarrays (TMAs) was performed at the Institute of Pathology of the Basel University Hospital (Basel, Switzerland). Immunohistochemistry was performed on deparaffinized formalin-fixed tissue using an automated staining system (Ventana Medical Systems, Tucson, AZ) or manually. Slides were heated with cell conditioner for antigen retrieval and endogenous biotin was blocked with a standard kit. Immunoreactivity was visualized with iVIEW DAB detection kit. Slides were counterstained with hematoxylin before glass coverslipping, and interpreted according to recent recommendations. ${ }^{29}$ The amyloid deposits of the "validation set" were classified immunohistochemically as described elsewhere. ${ }^{30}$

\section{LCP Synthesis and LCP Staining}

The synthesis of PTAA (mean mol. wt., mol. wt. $=3 \mathrm{kDa}$ ), tPTAA (mol. wt. $=1.5 \mathrm{kDa}$ ) and p-FTAA (mol. wt. $=615$ Da) have been reported elsewhere. ${ }^{31-33}$ Paraffin-embedded formalin fixed sections were deparaffinized. After rehydration with deionized water, the sections were equilibrated in PBS (p-FTAA staining) or $100 \mathrm{mmol} / \mathrm{L}$ sodium carbonate at $\mathrm{pH}=10$ (PTAA and tPTAA staining). LCPs were diluted in incubation buffer $(10 \mu \mathrm{g} / \mathrm{ml})$, added to the tissue sections, incubated for 30 minutes at room temperature, and removed by washes with incubation buffer.

\section{Fluorescence Microscopy and Spectral Analysis}

Images and spectra were recorded with a Zeiss Axioplan 2 microscope fitted with a Spectraview 4.0 (Applied Spectral Imaging, Migdal, Israel) and a Spectra-Cube (interferometrical optical head SD 300) module with cooled CCD-camera, through a 405/30-nm (LP 450) bandpass filter. The data were processed with SpectraView 3.0 EXPO software. Spectra were collected from LCP stained amyloid deposits (5-10 deposits for each sample and eight individual spots from each deposit) and other fluorescent entities. Fluorescent spectral unmixing (SUN) was performed using the function in the software. The spectra recorded for amyloid deposits in positive samples were used for SUN analysis of the negative control sample.

\section{Construction of Amyloid TMAs}

An amyloid TMA was constructed to investigate the LCP selectivity for amyloid. The TMA approach allows the direct comparison between many different subtypes of amyloids and negative controls within one small tissue cylinder. Paraffin-embedded tissues were selected for the TMA construction on the basis of Congo Red-stained tissue sections. Only tissue blocks with conspicuous amyloid deposits were used. Up to four cores $(0.6 \mathrm{~mm}$ in diameter; length: 3-4 $\mathrm{mm}$ ) were taken from each representative tissue block to increase the possibility of sufficient amyloid deposits in the tissue cores of the TMA. Cores from four different tissues without amyloidosis (heart, pancreas, spleen, and kidney) were included as negative control. The cores were transferred to the recipient paraffin block as described previously. ${ }^{34}$ Fourmicrometer-thick sections were cut for further analysis. There were sufficient amyloid deposits with positivity for both Congo Red and immunohistochemistry in tissue cores of 20 patients.

\section{Statistical Methods}

For spectral collection of PTAA bound to amyloid aggregates, tissue sections were analyzed as follows: eight individual spots within each of 5-10 plaques from each case were examined, yielding 30-50 measurements per case. The fluorescent intensity ratios were calculated $\left(R_{538} \mathrm{~nm} / \mathrm{Emax}\right.$ and $\left.R_{538 \mathrm{~nm} / 642 \mathrm{~nm}}\right)$, and mean and SD were recorded for each spectral ratio for each individual. To make up homogeneous groups of objects (classes) on the basis of their description by the two ratios, a k-means clustering analysis was performed (XLSTAT, 2008). In addition an unpaired, two-tailed Student's $t$-test was performed using mean values of single cases as observations (GraphPad Prism 5). The raw data from each individual case and the results from the statistical evaluations are provided as Supplemental Tables S1-S14 at $h t t p: / /$ ajp.amjpathol.org.

\section{Results}

\section{Immunohistochemical Amyloid Classification}

Amyloid deposits in 54 tissue samples from 42 patients were typed by immunohistochemistry on TMAs and on selected conventional tissue sections (Tables 1 and 2). For the nomenclature of amyloid and amyloidoses, we followed the recommendations by the International Nomenclature Committee on Amyloidosis. We stained TMA sections with $A A, A L$, or ATTR antibodies and scored immunohistochemical signals as interpretable only when they colocalized with unambiguous Congo Red signals.

When performing immunostains with antibodies to $A L$, we detected weak signals in all amyloid deposits. This is consistent with the reports that $\lg \lambda$-light chains frequently contaminates amyloid deposits of all types and can give rise to misinterpretations. ${ }^{13,20-23}$ Therefore, ALpositive samples were classified as AL amyloid only if they were negative for all other immunohistochemical amyloid stains (AA and ATTR). All other sections were initially stained with the AA antibody. If the samples were negative for AA, immunohistochemistry for ATTR and/or $\mathrm{AL}(\mathrm{m}-\kappa, \mathrm{p}-\kappa, \mathrm{m}-\lambda$, and $\mathrm{p}-\lambda)$ was performed. 
Table 1. Clinical Description and Tinctorial Properties of TMA Specimens

\begin{tabular}{|c|c|c|c|c|c|c|c|c|}
\hline Patient & Organ & Primary diagnosis & Age/Sex & $\begin{array}{l}\text { Congo } \\
\text { Red }^{*}\end{array}$ & $\mathrm{IHC}^{+}$ & PTAA $^{\ddagger}$ & tPTAA* & p-FTAA* \\
\hline 1 & Heart & Heart failure & $80 / \mathrm{M}$ & + & ATTR & 1 & + & + \\
\hline 2 & Heart & Lung carcinoma, atrial fibrillation & $85 / \mathrm{M}$ & + & ATTR & 1 & + & + \\
\hline 3 & Heart & Trauma & $84 / \mathrm{M}$ & + & ATTR & 1 & + & + \\
\hline 4 & Heart & Hepatocellular carcinoma, hypertension & $80 / \mathrm{M}$ & + & ATTR & 1 & + & + \\
\hline 5 & Heart & Hypertensive heart disease & 90/M & + & ATTR & 1 & + & + \\
\hline 6 & Heart & Myocardial amyloidosis, atrial fibrillation & $96 / \mathrm{M}$ & + & ATTR & 1 & + & + \\
\hline 7 & Heart & Chronic pneumonia & $85 / F$ & + & ATTR & 1 & + & + \\
\hline 8 & Esophagus & $\begin{array}{l}\text { Lung and prostate carcinoma, } \\
\text { rheumatoid arthritis }\end{array}$ & $77 / \mathrm{M}$ & + & AA & 2,3 & + & + \\
\hline 8 & Kidney & $\begin{array}{l}\text { Lung and prostate carcinoma, } \\
\text { rheumatoid arthritis }\end{array}$ & $77 / \mathrm{M}$ & + & AA & 2,3 & + & + \\
\hline 9 & Heart & Hypertensive heart disease & $82 / \mathrm{M}$ & + & ATTR & 1 & + & + \\
\hline 10 & Heart & Cardiomyopathy & $85 / \mathrm{M}$ & + & ATTR & 1 & + & + \\
\hline 11 & Heart & Primary amyloidosis & $84 / F$ & + & $\mathrm{AL}$ & 2 & + & + \\
\hline 12 & Heart & Multiple myeloma & $75 / F$ & + & $A L$ & 2 & + & + \\
\hline 12 & Tongue & Multiple myeloma & $75 / F$ & + & $A L$ & 2 & + & + \\
\hline 13 & Heart & Ileal adenocarcinoma & $75 / F$ & + & ATTR & 1 & + & + \\
\hline 14 & Kidney & Monoclonal gammopathy & 73/F & + & $\mathrm{AL}$ & 2 & + & + \\
\hline 15 & Seminal vesicle & Lung carcinoma & $73 / \mathrm{M}$ & + & $A L$ & 2 & + & + \\
\hline 16 & Heart & Cardiomyopathy & $88 / \mathrm{M}$ & + & ATTR & 1 & + & + \\
\hline 17 & Heart & Amyloidosis, myocardial infarction & 95/M & + & ATTR & 1 & + & + \\
\hline 18 & Heart & $\begin{array}{l}\text { Coronary heart disease, suspected } \\
\text { amyloidosis }\end{array}$ & $76 / \mathrm{M}$ & + & ATTR & 1 & + & + \\
\hline 19 & Stomach & Abdominal pain & $71 / \mathrm{M}$ & + & $\mathrm{AL}$ & 2 & + & + \\
\hline 20 & Heart & Suspected amyloidosis & $79 / \mathrm{M}$ & + & ATTR & 1 & + & + \\
\hline 21 & Heart & Trauma & $17 / F$ & - & - & - & - & - \\
\hline 21 & Pancreas & Trauma & $17 / F$ & - & - & - & - & - \\
\hline 21 & Spleen & Trauma & $17 / F$ & - & - & - & - & - \\
\hline 21 & Kidney & Trauma & $17 / F$ & - & - & - & - & - \\
\hline
\end{tabular}

*Positive or negative staining are represented with + or - , respectively.

${ }^{\dagger}$ Amyloid subtype according to immunohistochemistry (IHC).

*The numbers 1,2 , or 3 refer to the spectral classification of PTAA tingibility.

$\mathrm{M}$, male; F, female.

Of the 42 patients with amyloidosis studied here, immunohistochemical typing determined that 18 were ATTR, 18 were AL, and 6 were AA (Tables 1 and 2). The plausibility of immunohistochemical typing was corroborated by the evaluation of clinical diagnoses. For negative controls, we used 11 tissue samples from three patients with neoplastic diseases (multiple myeloma without amyloidosis; lung cancer), two patients with chronic inflammatory disorders (chronic obstructive pulmonary disease; gonarthrosis), one patient with lysosomal storage disease (Fabry's disease), and one young patient who died as a result of trauma and was devoid of any systemic or organ-specific amyloid (Tables 1 and 2).

\section{Selective Amyloid Detection by LCP}

In a first series of experiments, the sensitivity and selectivity of LCPs were tested with an amyloid TMA containing samples from 20 amyloidosis patients and one negative control. PTAA, tPTAA, and p-FTAA (Figure 1, A-C) identified all amyloid deposits that were stained by antibodies and Congo Red, whereas none of the negative control samples showed any LCP signal (Figure 2, A-D). Amyloid deposits stained with PTAA or TPTAA emitted yellow-red fluorescence, whereas p-FTAA emitted extremely intense green-yellow fluorescence.

We then recorded full visible-light emission spectra (450-700 nm) on excitation through a 405/30 long-pass filter (LP 450) from LCP-stained amyloid deposits with a Spectramax camera at intervals of $8-10 \mathrm{~nm}$ (Figure 3, A-D). These measurements confirmed that p-FTAA had its absolute emission maximum at a wavelength of $\sim 550$ $\mathrm{nm}$, whereas the emission maxima for PTAA and IPTAA were located at longer wavelengths (560-600 nm), thereby conferring a reddish hue to the emitted light. These spectral characteristics were used to deconvolute the signals obtained from the specimens by "SUN": those pixels in each region of interest that displayed an LCP characteristic emission spectrum were arbitrarily assigned to red (PTAA and tPTAA) or green ( $p$-FTAA) pseudocolor codes, whereas fluorescent structures with other emission spectra were not visualized (Figure 2).

We directly compared sequential, adjacent sections stained with Congo Red and examined for green birefringence with those stained with LCPs. We found it much easier to identify amyloid deposits using the LCP fluorescence. Owing to its very high quantum yield, p-FTAA proved to be the most sensitive dye. Whereas collagen typically gave rise to some confounding birefringence in negative control samples (Figure 2), collagen did not score positive with any of the LCP stains. Even if not expressed in strictly quantitative terms, these results indicate that LCP fluorescence was vastly more sensitive and displayed much better signal-to-noise ratios than inspection of Congo Red-stained sections under crosspolarized light. 
Table 2. Clinical Description and Tinctorial Properties of Additional Samples

\begin{tabular}{|c|c|c|c|c|c|c|}
\hline Patient & Organ & Clinical information & Age/Sex & Congo Red* & $\mathrm{HCC}^{+}$ & PTAA group ${ }^{\ddagger}$ \\
\hline 8 & Heart & Lung and prostate carcinoma, rheumatoid arthritis & $77 / \mathrm{M}$ & + & $\mathrm{AA}$ & 2,3 \\
\hline 8 & Lung & Lung and prostate carcinoma, rheumatoid arthritis & $77 / \mathrm{M}$ & +++ & AA & 2,3 \\
\hline 8 & Liver & Lung and prostate carcinoma, rheumatoid arthritis & 77/M & ++ & AA & 2,3 \\
\hline 8 & Colon & Lung and prostate carcinoma, rheumatoid arthritis & $77 / \mathrm{M}$ & ++ & AA & 2,3 \\
\hline 8 & Prostate & Lung and prostate carcinoma, rheumatoid arthritis & $77 / \mathrm{M}$ & ++ & AA & 2,3 \\
\hline 8 & Thyroid & Lung and prostate carcinoma, rheumatoid arthritis & $77 / \mathrm{M}$ & +++ & $A A$ & 2,3 \\
\hline 8 & Adrenal gland & Lung and prostate carcinoma, rheumatoid arthritis & $77 / \mathrm{M}$ & +++ & AA & 2,3 \\
\hline 8 & Parathyroid & Lung and prostate carcinoma, rheumatoid arthritis & $77 / \mathrm{M}$ & +++ & $A A$ & 2,3 \\
\hline 12 & Lung & Multiple myeloma & $75 / F$ & +++ & $\mathrm{AL}$ & 2 \\
\hline 22 & Lymph node & Lymphadenopathy & $49 / F$ & +++ & AA & 3 \\
\hline 23 & Kidney & Proteinuria, suspected amyloidosis & $36 / F$ & + & $\mathrm{AA}$ & 3 \\
\hline 24 & Kidney & Proteinuria & $17 / \mathrm{M}$ & + & AA & 3 \\
\hline 25 & Small intestine & Diarrhea, nephrotic syndrome & $38 / \mathrm{M}$ & +++ & $\mathrm{AA}$ & 3 \\
\hline 25 & Stomach & Diarrhea, nephrotic syndrome & $38 / \mathrm{M}$ & +++ & $A A$ & 3 \\
\hline 26 & Duodenum & Duodenal ulcer & $53 / \mathrm{M}$ & ++ & $\mathrm{AL}$ & 2 \\
\hline 27 & Duodenum & Suspected amyloid & $47 / \mathrm{M}$ & ++ & $A L$ & 2 \\
\hline 28 & Sigma colon & $\mathrm{AL}$ amyloidosis & $39 / F$ & + & $A L$ & 2 \\
\hline 29 & Heart & Suspected amyloidosis & 74/M & +++ & ATTR & 1 \\
\hline 30 & Heart & Suspected cardiomyopathy & $62 / \mathrm{M}$ & ++ & $\mathrm{AL}$ & 2 \\
\hline 31 & Heart & Heart failure, monoclonal gammopathy & $80 / \mathrm{M}$ & ++ & ATTR & 1 \\
\hline 32 & Heart & Coronary heart disease, suspected AL amyloidosis & $87 / \mathrm{M}$ & ++ & ATTR & 1 \\
\hline 33 & Heart & Proteinuria, diarrhea, arrhythmia & $77 / \mathrm{M}$ & +++ & $A L$ & 2 \\
\hline 34 & Heart & Multiple myeloma & $61 / F$ & ++ & $A L$ & 2 \\
\hline 35 & Heart & Multiple myeloma & $60 / F$ & +++ & ATTR & 1 \\
\hline 36 & Heart & Multiple myeloma & $68 / \mathrm{M}$ & ++ & $\mathrm{AL}$ & 2 \\
\hline 37 & Heart & Multiple myeloma & $90 / \mathrm{M}$ & + & $A L$ & 2 \\
\hline 38 & Heart & Multiple myeloma, nephrotic syndrome & $54 / \mathrm{M}$ & ++ & $\mathrm{AL}$ & 2 \\
\hline 39 & Joint capsule & Fibrosis & $67 / \mathrm{M}$ & +++ & AA & 3 \\
\hline 40 & Soft tissue & Amyloidosis & $71 / \mathrm{M}$ & ++ & $\mathrm{AL}$ & 2 \\
\hline 41 & Joint capsule & Arthritis & $70 / \mathrm{M}$ & ++ & $A L$ & 2 \\
\hline 42 & Conjunctiva & Smoldering lymphoma with $\mathrm{AL}$ amyloidosis & $63 / \mathrm{M}$ & +++ & $\mathrm{AL}$ & 2 \\
\hline 43 & Soft tissue & Suspected Ganglion, amyloid & $64 / \mathrm{M}$ & +++ & $\mathrm{AL}$ & 2 \\
\hline 44 & Heart & Multiple myeloma, heart disease & $57 / \mathrm{M}$ & - & Neg & Neg \\
\hline 45 & Heart & Multiple myeloma, heart failure & $31 / \mathrm{M}$ & - & Neg & Neg \\
\hline 46 & Joint capsule & Gonarthrosis & $74 / F$ & - & Neg & Neg \\
\hline 47 & Lung & Chronic obstructive pulmonary disease & $64 / F$ & - & Neg & Neg \\
\hline 48 & Lung & Suspected malignancy & $62 / F$ & - & Neg & Neg \\
\hline 49 & Stomach & Fabry's disease & $17 / \mathrm{M}$ & - & Neg & Neg \\
\hline 49 & Duodenum & Fabry's disease & $17 / \mathrm{M}$ & - & Neg & Neg \\
\hline
\end{tabular}

*Positive or negative staining are represented with + or - , respectively.

${ }^{\dagger}$ Amyloid subtype according to immunohistochemistry (IHC).

\#The numbers 1, 2, or 3 refer to the spectral classification of PTAA tingibility.

$\mathrm{M}$, male; $\mathrm{F}$, female.

\section{Spectral Assignment of Amyloid Deposits}

When examining samples stained with PTAA and excited with a 405/30 nm (LP 450) bandpass filter, we found obvious interindividual variation in the color of light emit-

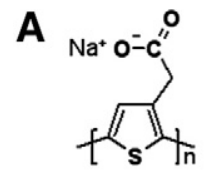

$n=11-20$

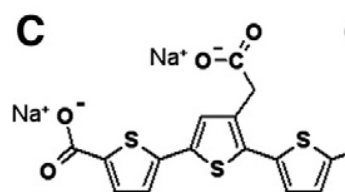

Figure 1. Chemical structures of the LCPs used in this study. PTAA (A) trimeric PTAA, tPTAA (B); and p-FTAA, pentameric formic thiophene acetic acid $(\mathbf{C})$. The number of monomeric units $(n)$ for the polydispersed LCPs was typically between 11 and 20 (PTAA) or 3 and 4 (tPTAA). All LCPs were synthesized as sodium salts, and all displayed anionic net charges under the staining conditions used in this study. ted by amyloid deposits. The formal analysis of their emission spectra revealed emission maxima for each deposit at either of the three wavelengths, 570, 580, and $590 \mathrm{~nm}$ (Figure 3). These signatures are known to reflect specific geometries of the LCP chains. Nonplanar, disperse LCP chains emit light $\sim 530-540 \mathrm{~nm}$, whereas planar transition of the backbones shifts their emission maximum toward longer wavelengths. This transition is often accompanied by stacking of the LCP chains, leading to intermolecular fluorescence resonance energy transfer and to a relative increase in emission intensity at $\sim 640-650 \mathrm{~nm}^{35-37}$ Therefore, we used the ratios of the intensity of the light emitted at the above wavelengths, $R_{538 / \text { max }}$ and $R_{538 / 642}$, as spectral surrogates for the conformation of amyloid-bound PTAA (Supplemental Tables S1 and S2, see http://ajp.amjpathol.org).

When plotting the values of the $R_{538 / E \max }$ and $R_{538 / 642}$ ratios for each of the amyloid deposit from the 42 patients, we found that each sample segregated into one of three sharply demarcated groups (Figure 3; details of the k-mean clustering analysis are reported 
A
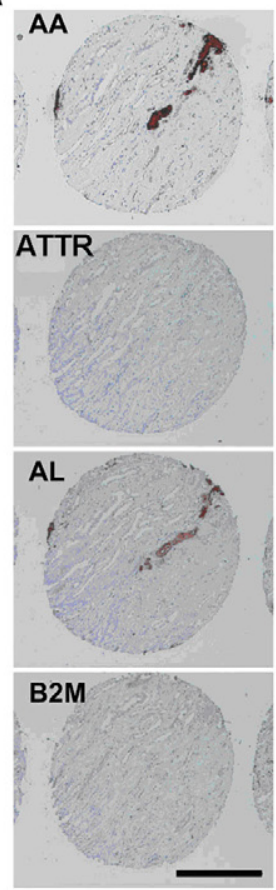

C

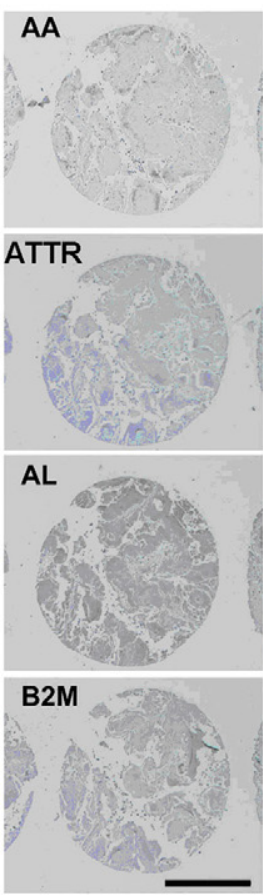

HE
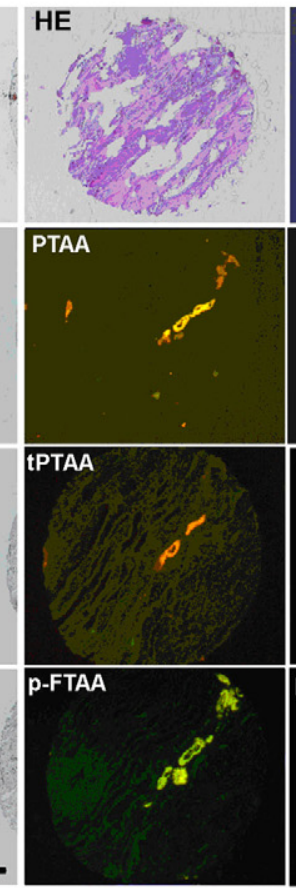

HE
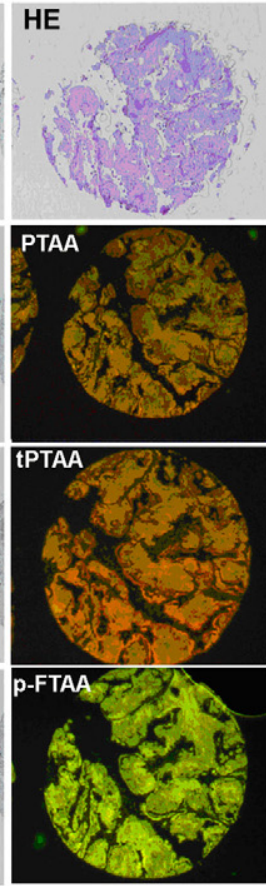

B
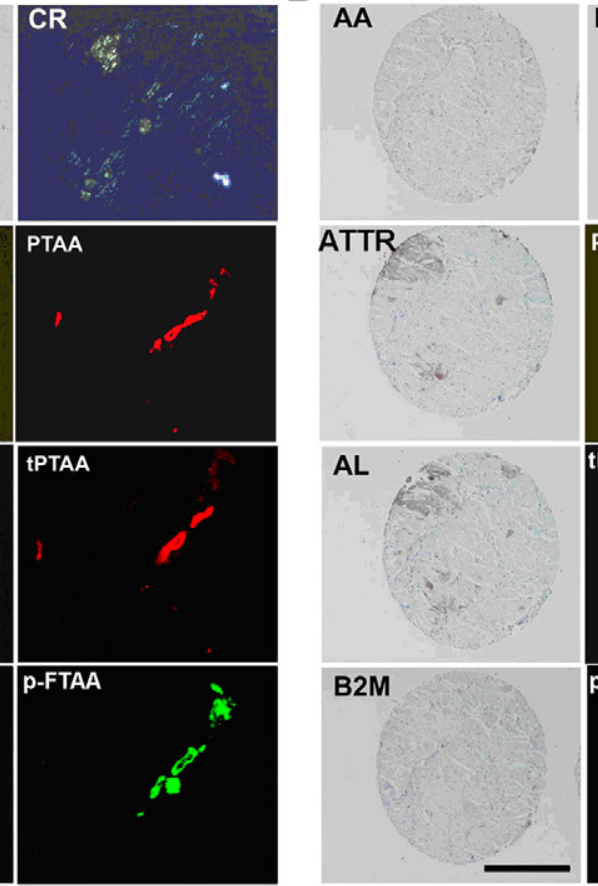

D
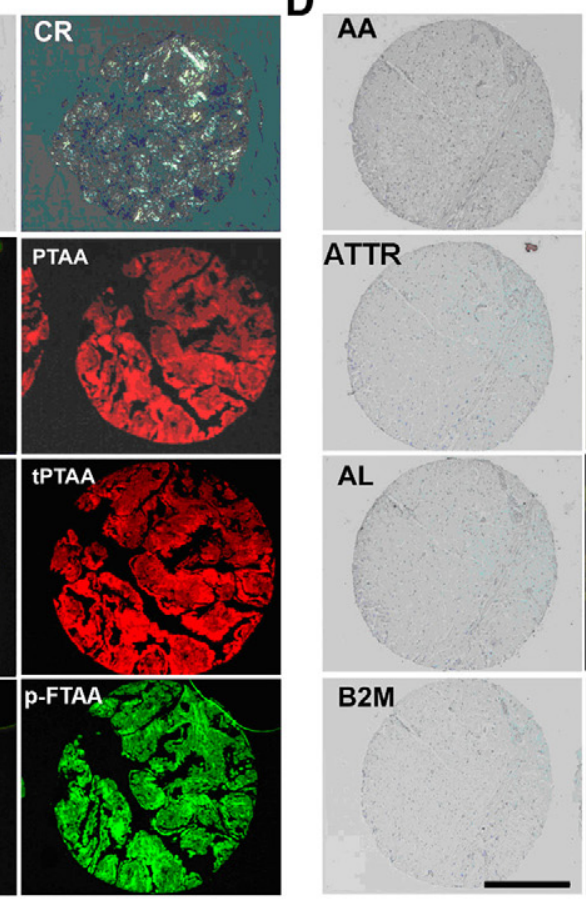
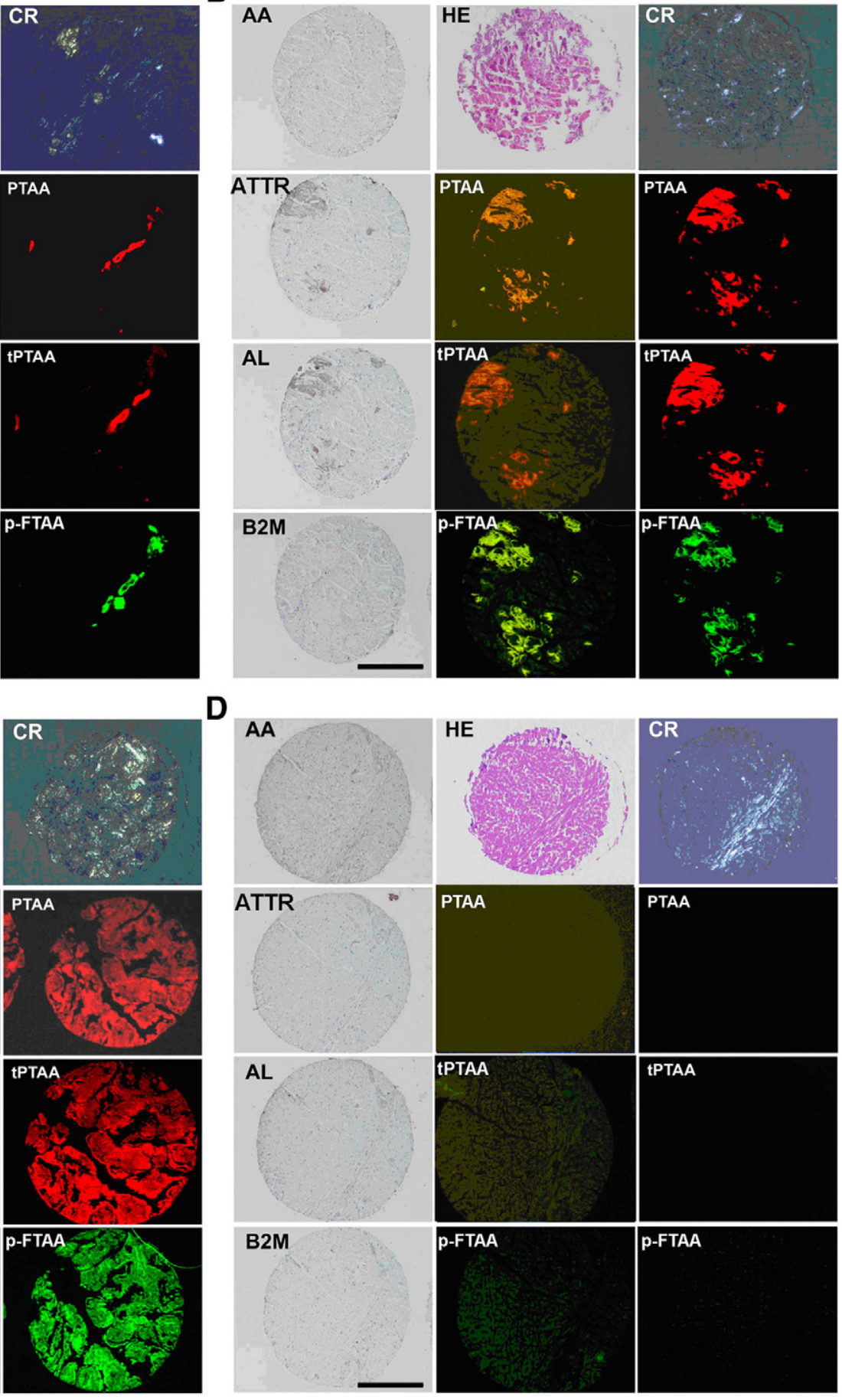

HE

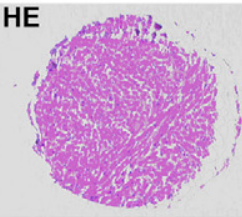

PTAA
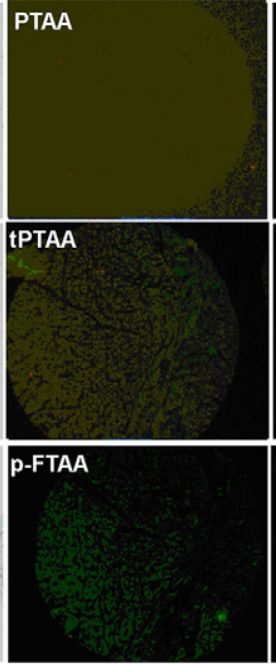
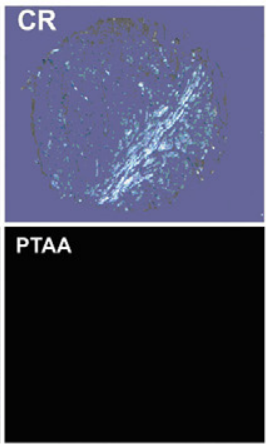

tPTAA

p-FTAA
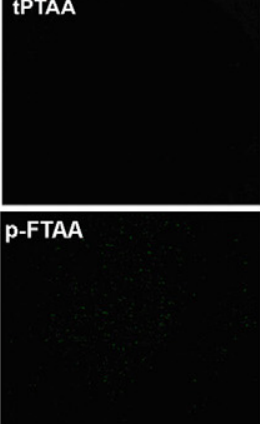

Figure 2. Immunohistochemical stains, Congo Red (CR) polarization microscopy, and LCP histochemistry of selected TMA spots. Each panel (A-D) depicts serial TMA sections stained with H\&E, antibodies to the relevant amyloid constituents (ATTR, AA, AL, B2M), and LCPs as indicated. The middle columns depict original fluorescent micrographs, whereas the panels on the right represent pseudocolor visualizations after SUN: PTAA and tPTAA signals are represented in red and pFTAA staining in green. A: Kidney sample of patient 8 who had been diagnosed with AA amyloidosis. B: Heart sample of patient 6 diagnosed with ATTR amyloidosis. C: Seminal vesicle sample of patient 15 diagnosed with AL. D: Heart specimen of patient 21 who did not suffer from amyloidosis (negative control). The silvery birefringent material in the CR stain consists of collagen fibers; this material does yield any signal in the LCP stains. Scale bars: $250 \mu \mathrm{m}$.

as Supplemental Tables S3-S8, see http://ajp.amjpathol. org). Similar but less dramatic spectral changes were observed for tPTAA, whereas the p-FTAA spectrum did not appreciably change on binding to the various amyloids (Figure 3).
We next compared the spectral data of PTAA with the immunohistochemical results. The spectral classification of all of the samples correlated with the amyloid type according to the immunohistochemical classification with PTAA group 1 for ATTR, PTAA group 2 for AL, and PTAA 
A

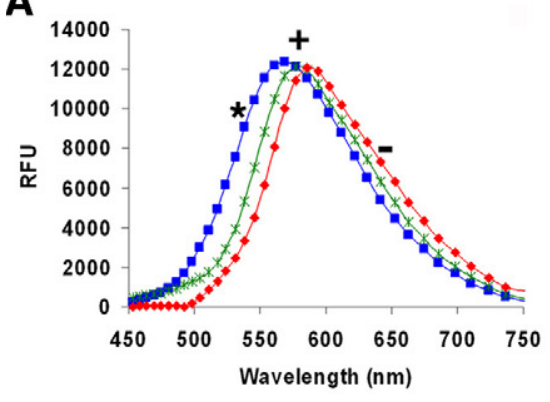

B

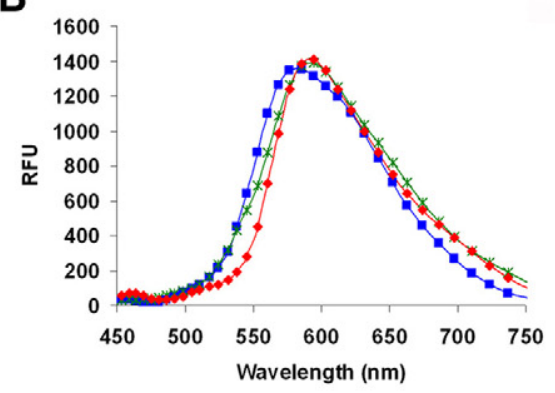

C

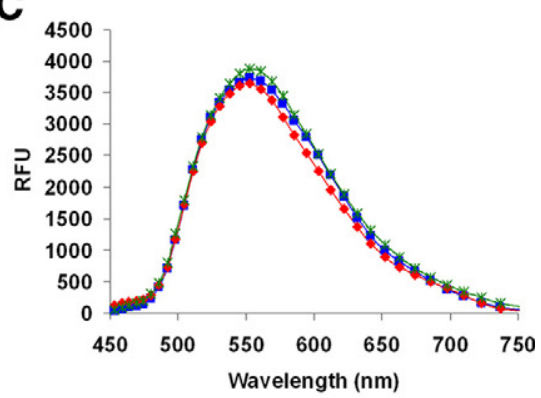

D

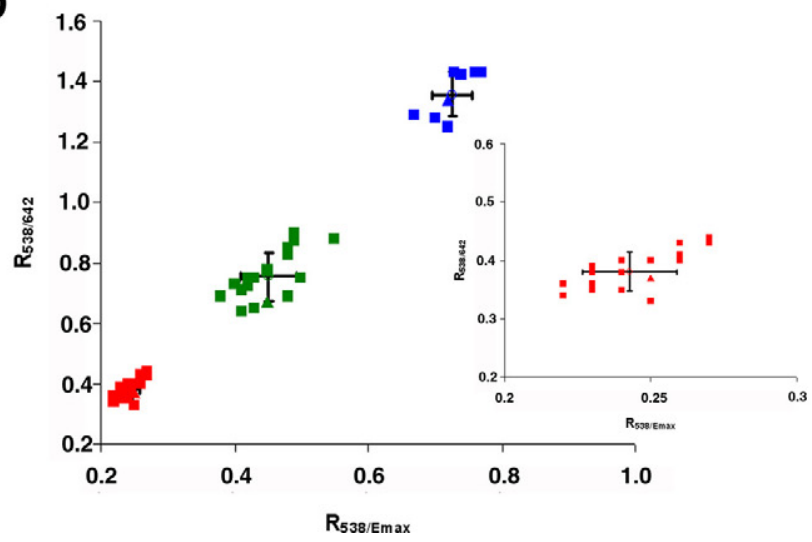

Figure 3. Characterization of the fluorescence emission of LCP-stained amyloid deposits. A-C: Representative spectra from amyloid deposits stained with PTAA (A), tPTAA (B), or p-FTAA (C). For PTAA, spectra with emission maxima at 570 (blue), 580 (green), or $590 \mathrm{~nm}$ (red) was observed. On staining with tPTAA and p-FTAA, differences between spectra were much more modest. Spectra were selected from samples (triangles) belonging to each of the three distinct groups observed in the correlation diagram of the spectral ratios. The wavelengths used for calculation of the spectral ratios $\mathrm{R}_{538 / \mathrm{Emax}}$ and $\mathrm{R}_{538 / 642}, 538 \mathrm{~nm}\left({ }^{*}\right)$, Emax (+) and $642 \mathrm{~nm}(-)$, respectively, are highlighted. D: Correlation diagram of the spectral ratios, $\mathrm{R}_{538 / \mathrm{Emax}}$ and $\mathrm{R}_{538 / 642}$, for PTAA from all cases that were stainable with CR. The mean value of eight spots from 5 to 10 individual amyloid deposits in each tissue section is represented as a square. The samples segregated into three nonoverlapping groups. Comparisons to immunohistochemical results revealed that these groups corresponded to AA (blue squares), AL (green squares), and ATTR (red squares) amyloidoses. The insert picture is showing a zoom in of the group corresponding to ATTR amyloidoses. The mean value and the SD for each group are shown as circles with black error bars. For statistical details and data for individual samples see Supplementary Tables S1-S8 at bttp://ajp.amjpathol.org.

group 3 for AA (Tables 1 and 2). Hence, the emission profiles of PTAA appear to reliably distinguish between amyloids of distinct biochemical subtypes. In one of the cases (patient 8), we found amyloid having two distinct PTAA spectra corresponding to groups 2 and 3 , whereas the immunohistochemical analysis only revealed $A A$ staining (Figure 4, A-F). Intriguingly, 10 different organs from this case were analyzed and all of them contained amyloid with two distinct PTAA spectra (Tables 1 and 2).

\section{Validation of the Spectral Assignment}

In a second set of experiments, the PTAA spectral classification was validated on a set of anonymous samples provided by an independent reference center. Samples consisted mostly of biopsies and resection specimens and were derived from 54 patients positive for $A L-\kappa, A L-\lambda$, ATTR, or AA amyloid. The spectral classification of the samples was compared with immunohistochemical typing and clinical diagnosis (Table 3; details of the spectral classification for individual samples are reported in Supplemental Tables S9 and S10 at http://ajp.amjpathol.org).

Forty-five cases (1 AA, 28 AL, and 16 ATTR) clustered in a similar fashion as described above (details of the k-mean clustering analysis for all PTAA classified samples are reported as Supplemental Tables S11-S14, see http://ajp.amjpathol.org), and the PTAA spectral assignment correlated with the immunohistochemical typing (Figure 5 and Table 3). Again, the amyloid deposits from one case that was immunopositive for AA yielded two distinct PTAA spectra corresponding to groups 2 and 3 , whereas amyloid in two other cases diagnosed as $A A$ showed PTAA spectra corresponding to group 2 (Figure 5 and Table 3).

Additionally, we identified three cases of amyloidosis that showed two distinct PTAA spectra in distinct regions of the respective histological specimen. Two of these cases could not be classified with immunohistochemical staining, as immunoreactivity was found for multiple antibodies. The third case displayed both PTAA spectra indicative of groups 1 (ATTR) and $2(\mathrm{AL})$ and was found to contain distinct amyloid deposits immunoreactive with antibodies to $\mathrm{AL}$ and ATTR amyloid. Hence, this case appears to represent a bona fide instance of mixed $A L$ and ATTR amyloidosis. In two cases diagnosed as AL, an extremely red-shifted emission was observed from the PTAA-stained amyloid deposits and those cases could not be classified according to any of the previously assigned groups, suggesting atypical pathogenesis. Finally, one case that proved nonclassifiable by immunotyping showed a PTAA spectrum correlating to group $2(A L)$.

\section{Discussion}

Immunohistochemistry is often regarded as the technique of choice for typing of amyloid, yet it is fraught with intrinsic limitations. Since amyloids consist of very tightly packed protein aggregates, they are often poorly accessible to antibodies. This degrades the quality and signalto-noise ratios of immunohistochemical stains. What is more, amyloid deposits often trap ancillary molecules including Igs and opsonins, ${ }^{38}$ which can interact with the 

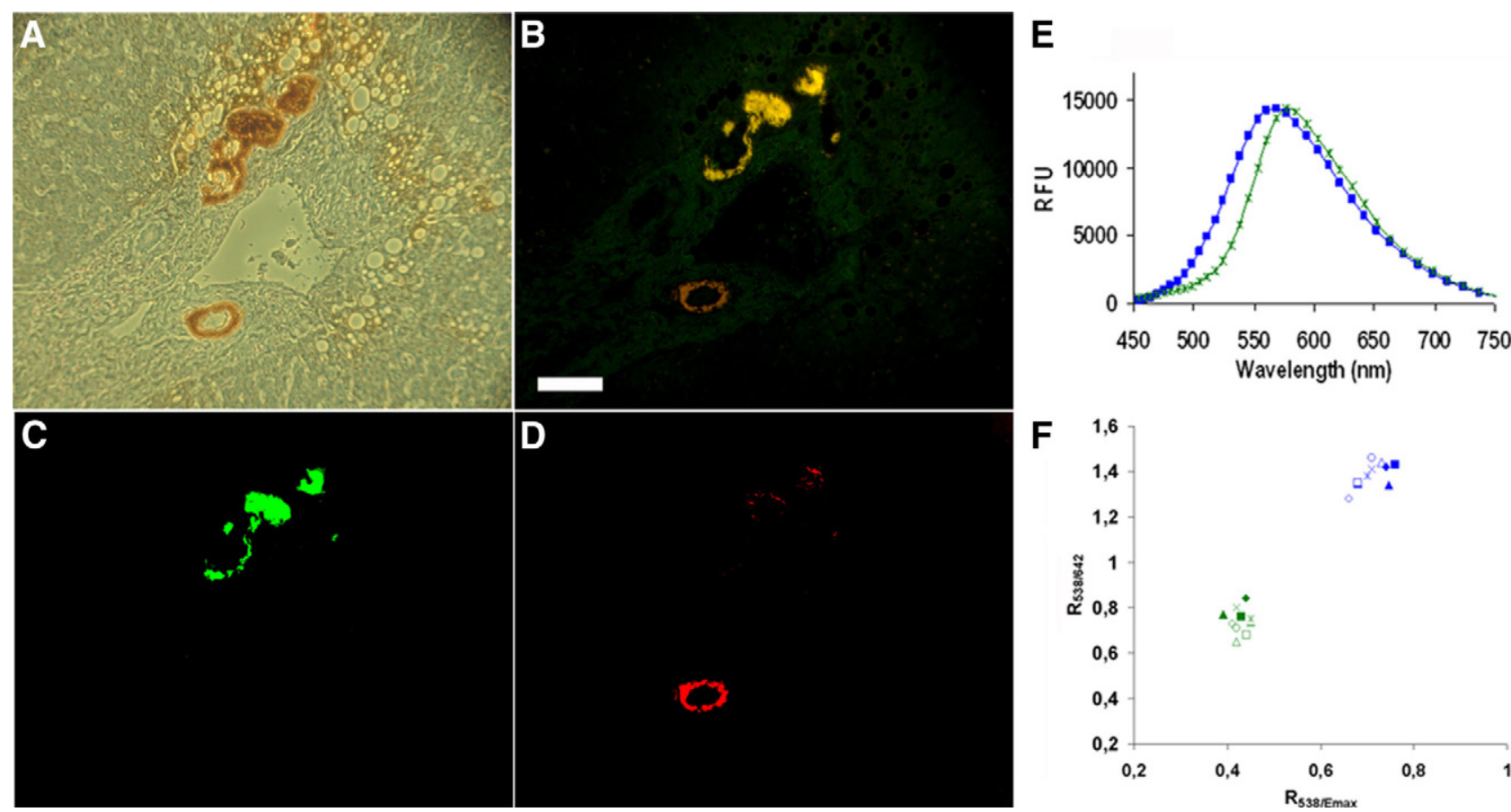

Figure 4. Immunohistochemical and PTAA staining of tissue with multiple spectral profiles. A: Bright-field image of a liver sample from patient 8 stained with antibodies against AA amyloid. Positive staining is observed in brown. B: Fluorescence image of a liver sample from patient 8 stained with PTAA. Positive staining is observed in yellow and yellow-red. $\mathbf{C}$ and $\mathbf{D}$ : Pseudocolor visualizations of two distinct types of amyloid deposits after SUN: PTAA signals are represented in green (blue spectrum) or red (green spectrum). E: Representative spectra from the two different amyloid deposits stained with PTAA. F: Correlation diagram of the spectral ratios, $\mathrm{R}_{538 / \mathrm{Emax}}$ and $\mathrm{R}_{538 / 642}$, for PTAA from 10 different tissue samples from patient 8 . All of the tissue samples had amyloid deposits with two distinct PTAA spectra showed in blue or green, respectively. The mean value of 10 spots from 5 to 10 individual amyloid deposits in each tissue section is represented by a symbol. Scale bar: $50 \mu \mathrm{m}$.

anti-Ig antibodies and protein A that are used for detection. These phenomena can cause considerable difficulties in the interpretation of immunohistochemical results, and can even lead to misclassification of amyloid subtypes. ${ }^{13,20-23}$

Thioflavins and Congo Red can reliably identify the presence of amyloid, but are chemically nondiscriminatory and therefore unsuitable for molecular subtyping. They also suffer from specific weaknesses ${ }^{39-41}$ : Congo Red staining leads to green birefringence in cross-polarized light but is not very sensitive and requires experience to reliably differentiate amyloids from a plethora of physiologically birefringent tissue constituents. The fluorescent dyes, thioflavin $T$ and $S$, are more sensitive than Congo Red, but their emission maxima in the blue range can overlap with the autofluorescence of tissue components. For all these reasons, it would be desirable to expand the arsenal of techniques available for the diagnosis of amyloidoses.

\section{Comparison between LCP Spectroscopy and Conventional Techniques}

LCPs bind preferentially to protein aggregates with repetitive cross $\beta$-sheet structures. ${ }^{24-28,32}$ In the present study, all amyloid deposits that were identified by Congo Red stains or immunohistochemistry were also recognized by LCPS, yet the LCP fluorescence was much easier to interpret than Congo Red birefringence. Similar observations were also made when studying prion strains, where LCP fluorescence was used to visualize noncongophilic protein aggregates. ${ }^{27}$ Of all tested LCPS, p-FTAA showed a particularly strong fluorescence on binding to amyloid deposits. As a further practical advantage, the p-FTAA staining is performed in PBS, allowing costaining with antibodies and p-FTAA.

As with all generic amyloid ligands, the tinctorial selectivity of LCPS for amyloid is not absolute. Ordered macromolecular aggregates with steric properties resembling those of amyloid may interact with LCPs as well. What sets LCPs apart from Congo Red and thioflavins, however, is their capacity to undergo characteristic spectral emission shifts when associated with amyloids. This property allows for separating amyloid-associated signals from autofluorescent tissue constituents, thus preventing the detection of false positives.

Changes of the relative orientation of thiophene rings within the LCP polymer backbones, and in the degree of stacking between individual polymer chains, affect the intensity of emitted light at characteristic wavelengths. ${ }^{35-37}$ Since such changes can occur on binding to aggregated proteins, the spectral signatures of LCPS can be used as surrogates for the molecular structure of the respective protein aggregates. These events can be visualized by fluorescence microscopy and, more precisely, by spectral analysis. ${ }^{24-28,32}$ Indeed, we found that various chemically defined amyloid subtypes yielded distinct spectroscopic PTAA signatures, a fact that can be practically used for typing amyloidoses and even heterogeneous amyloid deposits in individual samples. 
Table 3. Clinical Description and Tingibility of the Validation Set

\begin{tabular}{|c|c|c|c|c|c|}
\hline Patient & Organ & Diagnosis & Age/Sex & $\mathrm{HCC}^{*}$ & PTAA group ${ }^{\ddagger}$ \\
\hline A1 & Ureter & AL-amyloidosis $(\kappa)$ & $53 / F$ & $A L$ & 2 \\
\hline $\mathrm{A} 2$ & Rectum & AL-amyloidosis $(\kappa)$ & $79 / \mathrm{M}$ & $\mathrm{AL}$ & 2 \\
\hline A3 & Kidney & AL-amyloidosis $(\kappa)$ & $48 / F$ & $A L$ & 2 \\
\hline A4 & Colon & ATTR-amyloidosis & $72 / F$ & ATTR & 1 \\
\hline A5 & Liver & AL-amyloidosis $(\kappa)$ & $45 / F$ & $\mathrm{AL}$ & 2 \\
\hline A6 & Iliac crest & AL-amyloidosis $(\kappa)$ & $69 / \mathrm{M}$ & $A L$ & 2 \\
\hline A7 & Heart & ATTR-amyloidosis & $77 / \mathrm{M}$ & ATTR & 1 \\
\hline A8 & Colon & ATTR-amyloidosis & $71 / \mathrm{M}$ & ATTR & 1 \\
\hline A9 & Heart & ATTR-amyloidosis & $74 / \mathrm{M}$ & ATTR & 1 \\
\hline A10 & Iliac crest & AL-amyloidosis $(\kappa)$ & $77 / \mathrm{M}$ & $\mathrm{AL}$ & 2 \\
\hline A11 & Heart & ATTR-amyloidosis & $77 / \mathrm{M}$ & ATTR & 1 \\
\hline A12 & Heart & ATTR-amyloidosis & $71 / F$ & ATTR & 1 \\
\hline A13 & Heart & ATTR-amyloidosis & $74 / \mathrm{M}$ & ATTR & 1 \\
\hline A14 & Heart & ATTR-amyloidosis & $77 / \mathrm{M}$ & ATTR & 1 \\
\hline A15 & Tongue & AL-amyloidosis $(\kappa)$ & $58 / \mathrm{M}$ & $\mathrm{AL}$ & 2 \\
\hline A16 & Liver & AL-amyloidosis $(\lambda)$ & $59 / \mathrm{M}$ & $\mathrm{AL}$ & 2 \\
\hline A17 & Heart & ATTR-amyloidosis & $78 / \mathrm{M}$ & ATTR & 1 \\
\hline A18 & Skin & AL-amyloidosis $(\lambda)$ & $50 / F$ & $\mathrm{AL}$ & 2 \\
\hline A19 & Thyroid gland & AL-amyloidosis $(\lambda)$ & $47 / F$ & $\mathrm{AL}$ & 2 \\
\hline A20 & Tendon & ATTR-amyloidosis & $75 / \mathrm{M}$ & ATTR & 1 \\
\hline A21 & Heart & ATTR-amyloidosis & $65 / \mathrm{M}$ & ATTR & 1 \\
\hline A22 & Rectum & AL-amyloidosis $(\lambda)$ & $54 / \mathrm{M}$ & $\mathrm{AL}$ & 2 \\
\hline A23 & Colon & AL-amyloidosis $(\lambda)$ & $65 / F$ & $A L$ & 2 \\
\hline A24 & Lung & AL-amyloidosis $(\lambda)$ & $77 / \mathrm{M}$ & $A L$ & 2 \\
\hline A25 & Stomach & AL-amyloidosis $(\lambda)$ & $73 / F$ & $A L$ & 2 \\
\hline A26 & Heart & AL-amyloidosis $(\lambda)$ & $68 / F$ & $A L$ & 2 \\
\hline A27 & Heart & AL-amyloidosis $(\lambda)$ & $57 / \mathrm{M}$ & $A L$ & 2 \\
\hline A28 & Heart & AL-amyloidosis $(\kappa)$ & $58 / \mathrm{M}$ & $\mathrm{AL}$ & 2 \\
\hline A29 & Kidney & AL-amyloidosis $(\lambda)$ & $74 / \mathrm{M}$ & $A L$ & 2 \\
\hline A30 & Large intestine & ATTR-amyloidosis & $42 / \mathrm{M}$ & ATTR & 1 \\
\hline A31 & Stomach/duodenum & AL-amyloidosis $(\lambda)$ & $55 / \mathrm{M}$ & $\mathrm{AL}$ & 2 \\
\hline A32 & Lung & AL-amyloidosis $(\lambda)$ & $57 / F$ & $\mathrm{AL}$ & 2 \\
\hline A33 & Colon/A. temporalis & ATTR-amyloidosis & $81 / \mathrm{M}$ & ATTR & 1 \\
\hline A34 & Liver & AL-amyloidosis $(\lambda)$ & $65 / F$ & $A L$ & 2 \\
\hline A35 & Heart & AL-amyloidosis $(\lambda)$ & $67 / F$ & $A L$ & 2 \\
\hline A36 & Stomach & AL-amyloidosis $(\lambda)$ & $79 / \mathrm{M}$ & $\mathrm{AL}$ & 2 \\
\hline A37 & Colon & ATTR-amyloidosis & $55 / \mathrm{M}$ & ATTR & 1 \\
\hline A38 & Colon & AL-amyloidosis $(\kappa)$ & $78 / \mathrm{M}$ & $\mathrm{AL}$ & 2 \\
\hline A39 & Stomach & AL-amyloidosis $(\kappa)$ & $69 / \mathrm{M}$ & $\mathrm{AL}$ & 2 \\
\hline A40 & Liver & AL-amyloidosis $(\lambda)$ & $75 / F$ & $\mathrm{AL}$ & 2 \\
\hline A41 & Rectum & ATTR-amyloidosis & $86 / \mathrm{M}$ & ATTR & 1 \\
\hline A42 & Heart & ATTR-amyloidosis & $76 / \mathrm{M}$ & ATTR & 1 \\
\hline A43 & Heart & ATTR-amyloidosis & $70 / \mathrm{M}$ & ATTR & 1 \\
\hline A44 & Heart & AL amyloidosis $(\lambda)$ & 69/M & $\mathrm{AL}$ & 2 \\
\hline A45 & Duodenum & AA amyloidosis & $64 / \mathrm{M}$ & AA & 3 \\
\hline A46 & Colon & AA amyloidosis & $56 / \mathrm{M}$ & $A A$ & 2 \\
\hline A47 & Stomach & AA amyloidosis & $86 / F$ & AA & 2 \\
\hline A48 & Colon & AA amyloidosis & 68/M & AA & 2,3 \\
\hline A49 & Heart & Unclassifiable case ${ }^{c}$ & $42 / \mathrm{M}$ & $\mathrm{AL}$ & 2 \\
\hline A50 & Lymph node & Unclassifiable case ${ }^{c}$ & $77 / \mathrm{M}$ & $\mathrm{m} \cdot \mathrm{a}^{\dagger}$ & 1,2 \\
\hline A51 & Skin & Unclassifiable case ${ }^{c}$ & $50 / \mathrm{M}$ & $\mathrm{m} . \mathrm{a}^{\dagger}$ & 2,3 \\
\hline A52 & Heart & Mixed type of AL- $\lambda$ and ATTR & $73 / \mathrm{M}$ & ATTR and AL & 1,2 \\
\hline A53 & Iliac crest/heart & AL-Amyloidosis (kappa) & $67 / F$ & $\mathrm{AL}$ & N.C. \\
\hline A54 & Kidney & AL-Amyloidosis (lambda) & $56 / F$ & $A L$ & N. C. \\
\hline
\end{tabular}

*Amyloid subtype according to immunohistochemistry (IHC).

${ }^{\dagger}$ Amyloid deposits stained for multiple antibodies (m. a.).

FThe numbers 1, 2, or 3 refer to the spectral classification of PTAA tingibility.

N.C. $=$ Not classifiable; $M$, male; F, female.

Why does PTAA adopt different geometries on binding to specific amyloid types? Theoretical considerations ${ }^{42}$ and extrapolations from experiments with prion strains ${ }^{43}$ strongly suggest that PTAA conformations report directly on the variability of the supramolecular structures of the cognate protein aggregates. Accordingly, LCP histochemistry represents a powerful and relatively simple method for probing the structure of complex aggregates.
Alternatively, one might speculate that the phenomena visualized by PTAA staining depend on ancillary molecules associated with amyloid deposits. Many proteins and nonprotein components, such as serum amyloid $\mathrm{P}$ component, heparan sulfate proteoglycan, and complement constituents, can decorate amyloid deposits. ${ }^{44}$ The emission spectra of PTAA may be conceivably influenced by the relative contribution of these ancillary components 


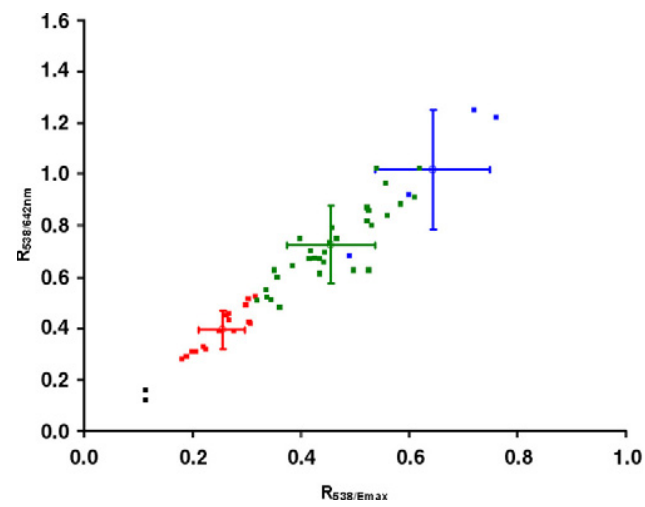

Figure 5. Validation of PTAA emission for amyloid typing. Correlation diagram of the spectral ratios, $\mathrm{R}_{538 / \mathrm{Emax}}$ and $\mathrm{R}_{538 / 642}$, for PTAA from 54 additional cases obtained from a second laboratory. The average value of eight spots from 5 to 10 individual amyloid deposits in each tissue section is represented as a square. The samples are visualized according to immunotyping: AA (blue squares), AL (green squares), and ATTR (red squares) amyloidoses. The mean value and the SD for each group are shown as circles with error bars. Two samples that were immunotyped as AL but that could not been classified according to PTAA emission are shown with a black box. For data for individual samples, see Supplemental Tables S9 and S10 at bttp://ajp.amjpathol.org.

to the PTAA-stained amyloid deposits. However, distinct PTAA spectra are recorded from amyloid fibrils of different morphologies generated in recombinant, chemically defined systems lacking all ancillary constituents. ${ }^{27}$ The latter observation strongly argues against the hypothesis that ancillary components specify PTAA spectra.

\section{Spectral Classification of Systemic Amyloidoses}

In total, 108 tissue samples from 96 cases were analyzed, and a perfect match between the PTAA spectral classification and the immunohistochemical typing was found for $86(89.6 \%)$ of these cases. These data position LCP spectroscopy as a useful methodology for amyloid subtyping. Optimal typing may be reached by combining LCP spectroscopy with immunohistochemistry, since antibodies identify specific chemical entities whereas LCP spectroscopy yields information on the conformational state of protein aggregates.

The group of amyloid deposits classified as AL displayed a considerable degree of spectral heterogeneity. Furthermore, two cases (A52 and A53) showed a reddish PTAA emission profile that could not be assigned to a distinct PTAA group. The protein underlying AL amyloid is a monoclonal immunoglobulin light chain whose composition depends on the stochastic rearrangement of the $\mathrm{V}$ and $\mathrm{J}$ genomic regions during B-cell maturation. Consequently, the primary sequence of monoclonal light chains varies radically between affected individuals. ${ }^{1,45}$ This sequence variability is likely to translate into structural variability of AL deposits, and it was speculated that it may contribute to defining the target tissue of $A L$ amyloid deposition. ${ }^{1,45}$ The spectral emission heterogeneity of PTAA-stained AL deposits is likely to be reflecting such variability. Despite their heterogeneity, the spectral characteristics from the AL-deposits were sufficiently distant from those of AA and ATTR amyloids to allow for reliable differentiation. It is tantalizing to speculate that the spe- cific structural features of individual $A L$ amyloid deposits, as revealed by specific PTAA emission spectra, may correlate with personalized clinical parameters.

In rare instances, more than one subtype of amyloid can coexist in the same individual. This phenomenon may be due, at least in part, to "cross-seeding" with oligomers of one protein providing a template for the aggregation of a second protein. ${ }^{46,47}$ We found LCP spectral assignment to be particularly useful in such instances. For example, case A52 was immunohistochemically classified as a mixed type of AL- $\lambda$ and ATTR, and showed two distinct PTAA spectra corresponding to these two amyloid subtypes. Therefore, the clinical and immunohistochemical diagnosis of combined amyloidosis was verified by LCP spectroscopy. Furthermore, we found multiple PTAA spectra in two cases that eluded unambiguous immunohistochemical typing because multiple antibodies tested positive, again providing strong independent evidence that more than one subtype of amyloid was present. Confirmative LCP staining of such cases may be highly relevant to clinical management, as difficulties in the interpretation of immunohistochemistry results and can lead to misclassification of amyloid subtypes. ${ }^{13,20-23}$

\section{Discrepancies between Immunotyping and PTAA Spectral Assignment}

Four cases that were immunotyped as AA amyloid displayed discrepant results with the two techniques. Two of these cases showed, in distinct areas, PTAA spectra corresponding to both groups 2 and 3, whereas immunotyping revealed only AA amyloid. This result may point to limitations in the specificity of LCP spectroscopy, or alternatively it may indicate a specific supramolecular conformation of the amyloid that went undetected by immunotyping. In two additional cases, immunotyping revealed $A A$ amyloid, yet were assigned to group 2 after PTAA spectral analysis. Maybe the atypical PTAA spectral signatures of these two cases reveal specific supramolecular conformations of AA amyloid. This is the case for prion strains, where distinct quaternary structures $^{48}$ of chemically equivalent $\mathrm{PrP}^{\mathrm{Sc}}$ aggregates gave rise to distinct clinical phenotypes and, in parallel, displayed unique PTAA spectral signatures. ${ }^{27}$ Analogously, the LCP emission profiles have been used for differentiation of multiple heterogeneous types of $A \beta$ deposits in the brain of a transgenic mouse model. ${ }^{28}$ Serum AA protein can be cleaved at multiple sites, and AA amyloid contains a diversity of truncated versions of the protein. ${ }^{14,49}$ In this context it will be of interest to analyze the prevalence of the various truncated forms of SAA in cases with atypic PTAA spectra.

The findings described above verify the use of LCPs as selective amyloid ligands, which provides a distinct spectroscopic read out of the conformational state of amyloid deposits. This property is not only important for verification of immunohistochemical clinical diagnosis but may also facilitate the study of amyloid origin, evolution and maturation. The latter studies are particularly 
topical, since it is emerging that many misfolded proteins can act similarly to prions or "prionoids." $4,50-56$ Furthermore, since LCPs appear to discriminate between conformational variants of protein aggregates, they may be of use in clarifying the pathogenetic importance of amyloid cross-seeding. ${ }^{57}$ Finally, the conformation of amyloid deposits might be determined by both seed morphology and host factors..$^{53}$ LCP spectroscopy may provide a powerful tool to dissect this issue.

\section{Limitations of LCP Spectroscopy}

In the present study and in previous investigations of prion strains ${ }^{27}$ we found that tissue fixation parameters can influence three crucial aspects of LCP histochemistry: the strength of amyloid-specific fluorescent signals, the structure-specific modulation of the emission spectra, and the amount of interfering formaldehyde-related shortwavelength autofluorescence. We found PTAA staining to be generally weaker on tissues that had been extensively exposed to fixatives, most probably as a direct consequence of excessive cross-linking of proteins with other constituents, or chemical modification of positively charged groups necessary for a strong interaction between PTAA and the amyloid deposits. This problem is by no means unique to LCPs: excessive fixation reduces dramatically the sensitivity of Congo Red stains ${ }^{58}$ and can completely abrogate thioflavin fluorescence. Antigen retrieval techniques, which are extensively used to enhance immunohistochemical signals on formaldehydefixed tissues, may prove useful for enhancing LCP stainings as well. Optimized preanalytical protocols for recovery, storage, and handling of samples will be essential to translate LCP spectroscopy into a clinically useful tool.

Formaldehyde-induced autofluorescence did not appear to represent an insurmountable problem. In the present study, we observed only one TMA spot with disturbingly intense blue autofluorescence. The case in question was also negative for Congo Red staining and was excluded from the analysis for the latter reason. The spectral signature of PTAA, and therefore the molecular subtyping, is more easily affected by excessive fixation than its overall fluorescence-perhaps because crosslinking fixatives distort the structure of protein aggregates, or renders them impermeable to LCPs. In a previous study of prion deposits associated with distinct prion strains, very mildly fixed cryosections was determined to yield the most informative fluorescence spectra. ${ }^{27}$ Since the availability of frozen material is often limited in routine clinical practice, the present study was performed on tissue fixed in $4 \%$ paraformaldehyde despite the caveats described above. Even under these fixation conditions, LCPs spectroscopy reliably distinguished between the three most common types of systemic amyloidoses. The highest signal-to-noise ratio and the optimal exploitation of the spectral features of LCPs, however, will only be achieved under controlled fixation conditions with specific non-cross-linking fixatives.

In conclusion, we have discovered that conformationsensitive amyloid-binding LCPs can be used not only for the sensitive visualization of amyloid but also for the differentiation of amyloid subtypes in tissue. The subtypespecific spectral fingerprints stem from the photophysical properties of LCPs, and cannot be obtained from any of the commonly used amyloid ligands. We foresee that LCPs, in combination with biochemical techniques and immunohistochemistry, will improve the precision of diagnoses of aggregation proteopathies, and will facilitate the study of amyloid origin and pathogenesis in humans and in animal models.

\section{Acknowledgments}

We thank Mrs. Silvia Behnke and Mrs. Martina Storz (Department of Pathology, University Hospital of Zurich, Switzerland), Rita Epper, and Stephan Dirnhofer (Institute for Pathology, University of Basel) for technical support with immunohistochemistry and TMA construction.

\section{References}

1. Enqvist S, Sletten K, Stevens FJ, Hellman U, Westermark P: Germ line origin and somatic mutations determine the target tissues in systemic AL-amyloidosis. PLoS ONE 2007, 2:e981

2. Chiti F, Dobson CM: Protein misfolding, functional amyloid, and human disease. Annu Rev Biochem 2006, 75:333-366

3. Maji SK, Perrin MH, Sawaya MR, Jessberger S, Vadodaria K, Rissman RA, Singru PS, Nilsson KPR, Simon R, Schubert D, Eisenberg D, Rivier J, Sawchenko P, Vale W, Riek R: Functional amyloids as natural storage of peptide hormones in pituitary secretory granules. Science 2009, 325:328-332

4. Aguzzi A: Cell biology: Beyond the prion principle. Nature 2009, 459:924-925

5. Aguzzi A, Haass C: Games played by rogue proteins in prion disorders and Alzheimer's disease. Science 2003, 302:814-818

6. Aguzzi A, Polymenidou M: Mammalian prion biology: one century of evolving concepts. Cell 2004, 116:313-327

7. Dember LM: Emerging treatment approaches for systemic amyloidoses. Kidney Int 2005, 68:1377-1390

8. Comenzo RL: Current and emerging views and treatments of systemic immunoglobulin light-chain (AL) amyloidosis. Contrib Nephrol 2007, 153:195-210

9. Westermark P, Benson MD, Buxbaum JN, Cohen AS, Frangione B, Ikeda S, Masters CL, Merlini G, Saraiva MJ, Sipe JD: A primer of amyloid nomenclature. Amyloid 2007, 14:179-183

10. Obici L, Perfetti V, Palladini G, Moratti R, Merlini G: Clinical aspects of systemic amyloid diseases. Biochim Biophys Acta 2005, 1753:11-22

11. Sanchorawala $\mathrm{V}$ : Light-chain (AL) amyloidosis: diagnosis and treatment. Clin J Am Soc Nephrol 2006, 6:1331-1341

12. Sanchorawala V, Blanchard E, Seldin DC, O'Hara C, Skinner M, Wright DG: AL amyloidosis associated with B-cell lymphoproliferative disorders: frequency and treatment outcomes. Am J Hematol 2006, 81:692-695

13. Picken MM: New insights into systemic amyloidosis: the importance of diagnosis of specific type. Curr Opin Nephrol Hypertens 2007, 16:196-203

14. Röcken C, Shakespeare A: Pathology, diagnosis and pathogenesis of AA amyloidosis. Virchows Arch 2002, 440:111-122

15. Lachmann HJ, Hawkins PN: Systemic amyloidosis. Curr Opinion Pharmacol 2006, 6:1-7

16. Pitkänen $P$, Westermark $P$, Cornwell GG: Senile systemic amyloidosis Am J Path 1984, 117:391-399

17. Johansson B, Westermark P: Senile systemic amyloidosis: a clinicopathological study of twelve patients with massive amyloid infiltration. Int J Cardiol 1991, 32:83-92

18. Hawkins PN: Hereditary systemic amyloidoses with renal involvement. J Nephrol 2003, 16:443-448 
19. Ando Y, Nakamura M, Araki S: Transthyretin-related familial amyloidotic polyneuropathy. Arch Neurol 2005, 62:1057-1062

20. Lachmann HJ, Booth DR, Booth SE, Bybee A, Gilbertson JA, Gillmore JD, Pepys MB, Hawkins PN: Misdiagnosis of hereditary amyloidosis as AL (primary) amyloidosis. N Engl J Med 2002, 346:1786-1791

21. Novak L, Cook WJ, Herrera GA, Sanders PW: AL-amyloidosis is underdiagnosed in renal biopsies. Nephrol Dial Transplant 2004, 19:3050-3053

22. Kebbel A, Röcken C: Immunohistochemical classification of amyloid in surgical pathology revisited. Am J Surg Pathol 2006, 30:673-683

23. Satoskar AA, Burdge K, Cowden DJ, Nadasdy GM, Hebert LA, Nadasdy T: Typing of amyloidosis in renal biopsies-diagnostic pitfalls. Arch Pathol Lab Med 2007, 131:917-922

24. Nilsson KPR, Herland A, Hammarström P, Inganäs O: Conjugated polyelectrolytes: conformation-sensitive optical probes for detection of amyloid fibril formation. Biochemistry 2005, 44:3718-3724

25. Herland A, Nilsson KPR, Olsson JDM, Hammarström P, Konradsson $P$, Inganäs $O$ : Synthesis of a regioregular zwitterionic conjugated oligoelectrolyte, usable as an optical probe for detection of amyloid fibril formation at acidic pH. J Am Chem Soc 2005, 127:2317-2323

26. Nilsson KPR, Hammarström P, Ahlgren F, Herland A, Schnell EA, Lindgren M, Westermark GT, Inganäs O: Conjugated polyelectrolytes-conformation-sensitive optical probes for staining and characterization of amyloid deposits. Chembiochem 2006, 7:1096-1104

27. Sigurdson CJ, Nilsson KPR, Hornemann S, Manco G, Polymenidou M, Schwarz P, Leclerc M, Hammarström P, Wuthrich K, Aguzzi A: Prion strain discrimination using luminescent conjugated polymers. Nat Methods 2007, 4:1023-1030

28. Nilsson KPR, Åslund A, Berg I, Nyström S, Konradsson P, Herland A, Inganäs $\mathrm{O}$, Stabo-Eeg $\mathrm{F}$, Lindgren M, Westermark GT, Lannfelt L, Nilsson LN, Hammarström P: Imaging distinct conformational states of amyloid- $\beta$ fibrils in Alzheimer's disease using novel luminescent probes. ACS Chem Biol 2007, 2:553-560

29. Linke RP, Oos R, Wiegel NM, Nathrath WB: Classification of amyloidosis: misdiagnosing by way of incomplete immunohistochemistry and how to prevent it. Acta Histochem 2006, 108:197-208

30. Eriksson M, Buttner J, Todorov T, Yumlu S, Schonland S, Hegenbart U, Kristen AV, Dengler T, Lohse P, Helmke B, Schmidt H, Röcken C: Prevalence of germline mutations in the TTR gene in a consecutive series of surgical pathology specimens with ATTR amyloid. Am J Surg Pathol 2009, 33:58-65

31. Åslund A, Herland A, Hammarström P, Nilsson KPR, Jonsson B-H, Konradsson $\mathrm{P}$, Inganäs $\mathrm{O}$ : Studies of luminescent conjugated polythiophene derivatives: enhanced spectral discrimination of protein conformational states. Bioconjug Chem 2007, 18:1860-1868

32. Åslund A, Sigurdson CJ, Klingstedt T, Grathwohl S, Bolmont T, Dickstein DL, Glimsdal E, Prokop S, Lindgren M, Konradsson P, Holtzman DM, Hof PR, Heppner FL, Gandy S, Jucker M, Aguzzi A, Hammarström P, Nilsson KPR: Novel pentameric thiophene derivatives for in vitro and in vivo optical imaging of a plethora of protein aggregates in cerebral amyloidoses. ACS Chem Biol 2009, 4:673-684

33. Ding LJM, Roman LS, Andersson MR, Inganäs O: Photovoltaic cells with a conjugated polyelectrolyte. Synt Met 2000, 110:133-140

34. Bubendorf L, Nocito A, Moch H, Sauter G: Tissue microarray (TMA) technology: miniaturized pathology archives for high-throughput in situ studies. J Pathol 2001, 195:72-79

35. Andersson MR, Berggren M, Olinga T, Hjertberg T, Inganäs $O$, Wennerström O: Improved photoluminescence efficiency of films from conjugated polymers. Synthetic Metals 1997, 85:1383-1384

36. Berggren $M$, Bergman $P$, Fagerstrom J, Inganäs $O$, Andersson $M$, Weman H, Granström M, Stafström S, Wennerström O, Hjertberg T: Controlling inter-chain and intra-chain excitations of a poly(thiophene) derivative in thin films. Chem Phys Lett 1999, 304: 84-90

37. Nilsson KPR, Andersson MR, Inganäs O: Conformational transitions of a free amino-acid-functionalized polythiophene induced by different buffer systems. J Phys Condens Matter 2002, 14:10011-10020

38. Klein MA, Kaeser PS, Schwarz P, Weyd H, Xenarios I, Zinkernagel RM, Carroll MC, Verbeek JS, Botto M, Walport MJ, Molina H, Kalinke
$\mathrm{U}$, Acha-Orbea $\mathrm{H}$, Aguzzi A: Complement facilitates early prion pathogenesis. Nat Med 2001, 7:488-492

39. Harper JD, Lansbury PT, Jr.: Models of amyloid seeding in Alzheimer's disease and scrapie: mechanistic truths and physiological consequences of the time-dependent solubility of amyloid proteins. Annu Rev Biochem 1997, 66:385-407

40. Harper JD, Wong SS, Lieber CM, Lansbury PT: Observation of metastable $A \beta$ amyloid protofibrils by atomic force microscopy. Chem. Biol 1997, 4 119-125

41. Westermark GT, Johnson KH, Westermark P: Staining methods for identification of amyloid in tissue. Methods Enzymol 1999, 309:3-25

42. Aguzzi A: Unraveling prion strains with cell biology and organic chemistry, Proc Natl Acad Sci USA 2008, 105:11-12

43. Aguzzi A, Sigurdson C, Heikenwalder M: Molecular mechanisms of prion pathogenesis. Annu Rev Pathol 2008, 3:11-40

44. Sipe JD, Cohen AS: History of the amyloid fibril. J Struct Biol 2000 130:88-98

45. Bellotti V, Mangione P, Merlini G: Immunoglobulin light chain amyloidosis - the archetype of structural and pathogenic variability. J Struct Biol 2000, 130:280-289

46. Furukawa Y, Kaneko K, Matsumoto G, Kurosawa M, Nukina N: Crossseeding fibrillation of $\mathrm{Q} / \mathrm{N}$-rich proteins offers new pathomechanism of polyglutamine diseases. J Neurosci 2009, 29:5153-5162

47. Yan J, Fu X, Ge F, Zhang B, Yao J, Zhang H, Qian J, Tomozawa H, Naiki H, Sawashita J, Mori M, Higuchi K: Cross-seeding and crosscompetition in mouse apolipoprotein A-II amyloid fibrils and protein A amyloid fibrils. Am J Pathol 2007, 171:172-180

48. Aguzzi A: Staining, straining and restraining prions. Nat Neurosci 2008, 11:1239-1240

49. Röcken C, Menard R, Buhling F, Vockler S, Raynes J, Stix B, Kruger $\mathrm{S}$, Roessner A, Kahne T: Proteolysis of serum amyloid $A$ and $A A$ amyloid proteins by cysteine proteases: cathepsin B generates AA amyloid proteins and cathepsin $\mathrm{L}$ may prevent their formation. Ann Rheum Dis 2005, 64:808-815

50. Enqvist S, Mellqvist UH, Molne J, Sletten K, Murphy C, Solomon A Stevens FJ, Westermark P: A father and his son with systemic AL amyloidosis. Haematologica 2009, 94:437-439

51. Westermark P, Lundmark K, Westermark GT: Fibrils from designed non-amyloid-related synthetic peptides induce AA-amyloidosis during inflammation in an animal model. PLoS ONE 2009, 4:e6041

52. Kane MD, Lipinski WJ, Callahan MJ, Bian F, Durham RA, Schwarz $\mathrm{RD}$, Roher AE, Walker LC: Evidence for seeding of $\beta$-amyloid by intracerebral infusion of Alzheimer brain extracts in $\beta$-amyloid precursor protein-transgenic mice. J Neurosci 2000, 20:3606-3611

53. Meyer-Luehmann M, Coomaraswamy J, Bolmont T, Kaeser $\mathrm{S}$, Schaefer C, Kilger E, Neuenschwander A, Abramowski D, Frey P, Jaton AL, Vigouret JM, Paganetti P, Walsh DM, Mathews PM, Ghiso J, Staufenbiel M, Walker LC, Jucker M: Exogenous induction of cerebral $\beta$-amyloidogenesis is governed by agent and host. Science 2006, 313:1781-1784

54. Ren PH, Lauckner JE, Kachirskaia I, Heuser JE, Melki R, Kopito RR: Cytoplasmic penetration and persistent infection of mammalian cells by polyglutamine aggregates. Nat Cell Biol 2009, 11:219-225

55. Clavaguera F, Bolmont T, Crowther RA, Abramowski D, Frank $S$, Probst A, Fraser G, Stalder AK, Beibel M, Staufenbiel M, Jucker M, Goedert M, Tolnay M: Transmission and spreading of tauopathy in transgenic mouse brain. Nat Cell Biol 2009, 11:909-913:

56. Li JY, Englund E, Holton JL, Soulet D, Hagell P, Lees AJ, Lashley T, Quinn NP, Rehncrona S, Bjorklund A, Widner H, Revesz T, Lindvall O, Brundin P: Lewy bodies in grafted neurons in subjects with Parkinson's disease suggest host-to-graft disease propagation. Nat Med 2008, 14:501-503

57. Lundmark K, Westermark GT, Olsen A, Westermark P: Protein fibrils in nature can enhance amyloid protein $\mathrm{A}$ amyloidosis in mice: crossseeding as a disease mechanism. Proc Natl Acad Sci USA 2005, 102:6098-6102

58. Röcken C, Sletten K: Amyloid in surgical pathology. Virchows Arch 2003, 443:3-16 